\title{
Wohlfahrtsökonomie und Konsumentensouveränität
}

\author{
ALEXANDER LORCH ${ }^{*}$
}

Rezension zu Karsten Witt (2012): Woblfahrt und Freibeit. Eine Kritik an der Rechtfertigung freier Märkte, Frankfurt a.M., New York: Campus Verlag.

Der Klappentext des Buchs verspricht Großes: eine kritische Auseinandersetzung mit „einer der einflussreichsten Ideen der Gegenwart: dem Wirtschaftsliberalismus“. Der Autor selbst beschreibt sein Vorhaben als „Versuch einer philosophischen Kritik“ (S. 12) des ökonomischen Gedankengebäudes, mit dem Ziel, „,die Zukunft der wohlfahrtsökonomischen ethischen Thesen“ (S. 21) zur Diskussion zu stellen.

\section{Kritik an der Wohlfahrtsökonomie}

Die zentrale These des Autors ist, dass freie Märkte in ihrer heutigen Form wohlfahrtsökonomisch nicht rechtfertigbar seien - selbst, wenn man „wohlfahrtsökonomisch" weit auslege (S. 27f.). Die umfangreiche Abhandlung der zeitgenössischen Wohlfahrtsökonomie in Kapitel 2 macht dabei aber deutlich, dass der Autor prinzipiell an der Argumentation der neoklassisch begründeten Wohlfahrtsökonomie festhalten möchte und auch nur in deren Rahmen argumentiert - was wichtig für das Verständnis seiner Argumentation ist.

Problematisch an der Wohlfahrtsökonomie ist für Witt, dass sie sowohl von Konsumentensouveränität als auch von freien Märkten ausgeht. Dies ist für den Autor ein Widerspruch, an dem sich die folgende Debatte entzündet. Das Argument ist dabei durchaus überzeugend: Aufgrund von Informationsasymmetrien und irreführender Werbung könne in freien, unregulierten Märkten keine Rede von Konsumentensouveränität sein - der Konsument werde vielmehr durch Werbung so stark beeinflusst, dass der Konsumismus als Lifestyle andere Überlegungen des guten Lebens verdränge und somit die Freiheit des Einzelnen, einen selbstgewählten Lebensentwurf zu verfolgen, beeinträchtigt werde. Die Konsumentensouveränität sei aber für die Wohlfahrtsökonomie zentral und verdiene darum einer näheren Betrachtung, die die Standardökonomik derzeit nicht liefere.

\section{2. $\quad$ Konsum und Wohlfahrt}

Die Lösung liegt für Witt darin, die Konsumentensouveränität fortan zu einem Prinzip zu erklären (S. 71f.), das mit Hilfe von Mills negativem Freiheitsverständnis gerechtfertigt und mit seinen Überlegungen zu Freiheit und Authentizität angereichert wird (Kapitel 5). Die Debatte über Authentizität, Selbstbestimmung und -ver-

Dr. Alexander Lorch, Institut für Wirtschaftsethik, Universität St.Gallen, Tannenstrasse 19, CH-9000 St.Gallen, Tel.: +41-(0)71 22431 08, Fax: +41-(0)71 22428 81, E-Mail: alexander.lorch@unisg.ch, Forschungsschwerpunkte: Wirtschaftsethik, politische Philosophie, Ordnungsethik und Ordnungspolitik, Soziale Marktwirtschaft. 
wirklichung und deren Auswirkung bzw. Verschränkung mit Wohlfahrtsargumenten (Kapitel 6, 7 und 8) führt dann schlussendlich zu einem Plädoyer für eine „,werbereduzierte Marktwirtschaft“" (S. 233). Um die Modellannahmen der Wohlfahrtsökonomie von Konsumentensouveränität und freier Marktwirtschaft zu retten, muss das Modell nach Witt nämlich um eine kritische Betrachtung beeinflussender Werbemaßnahmen (im weitesten Sinne), die den Konsumenten in der Verfolgung seines je individuellen Lebensentwurfs beeinflussen, ergänzt werden. So ließen sich die übrigen wohlfahrtsökonomischen Prämissen aufrechterhalten und mit der Forderung nach Konsumentensouveränität schlüssig verknüpfen. Theoretisch bedeutet dies also eine punktuelle Einschränkung der Annahme der freien Marktwirtschaft in Form von erlaubten staatlichen Eingriffen bei irreführender Werbung - politisch eine weitgehende Kontrolle sowie ein mögliches Verbot dieser Werbeformen.

\section{Kritische Würdigung}

Witt hat sich aus dem großen Gedankengebäude der Wohlfahrtsökonomie mit der Konsumentensouveränität einen bestimmten Aspekt herausgesucht, der ihm nicht schlüssig scheint, ihn aufwendig und ausführlich beleuchtet und kritisiert sowie konstruktiv um eine konsumismuskritische Erwägung ergänzt. Als solche ist sein Werk schlüssig und seine Argumentation nachvollziehbar geführt.

Etwas weniger schlüssig scheint die angekündigte „kritische, interdisziplinär fundierte Auseinandersetzung mit (...) dem Wirtschaftsliberalismus" (Klappentext). Denn im Grunde bleiben alle Axiome dieser neoliberalen Ideologie, die ja nicht unwesentlich auf den theoretischen Überlegungen der Wohlfahrtsökonomie fußt, unberührt. Eine philosophische Auseinandersetzung mit den fundamentalen Grundannahmen des Wirtschaftsliberalismus fehlt: So wird die Ignoranz des Utilitarismus bezüglich Verteilungsfragen zwar erwähnt, aber nicht weiter diskutiert oder das Pareto-Kriterium mitgetragen. Letztlich fehlt eine wirklich kritische Auseinandersetzung mit allen anderen normativen Prämissen der Wohlfahrtsökonomie außer der Konsumentensouveränität. Dies wird vom Autor alles thematisiert, aber mit dem Hinweis auf die bewusst auf die Wohlfahrtsökonomie begrenzte Debatte ad acta gelegt und folglich in Kauf genommen.

Es ist bedauerlich, dass sich der Autor tatsächlich weitestgehend nur in der Theorie der Wohlfahrtsökonomie und der philosophischen Tradition des Utilitarismus aufhält. Von einem Buch, dass eine „Kritik der Rechtfertigung freier Märkte“ verspricht und in der Einleitung eine philosophische Kritik ankündigt, hätte man erwartet, dass es zumindest die wirtschaftsethischen Debatten, die dieses Vorhaben ganz explizit berührt, zur Kenntnis nimmt: So fehlt bspw. eine umfassende Kritik der ökonomischen Theorie (vgl. Ulrich 1993; 2008) oder eine Auseinandersetzung mit dem Prinzip Markt und dem Pareto-Kriterium (vgl. Thielemann 1996; 2010). Vor allem aber sind keinerlei wirtschaftsethische Schriften zu Konsumentenethik und -souveränität zur Kenntnis genommen worden, die die Auseinandersetzung von Witt ja ganz unmittelbar berühren (vgl. bspw. Knobloch 1994, Michel 1997 oder aktuell Harrison et al. 2005 sowie Heidbrink et al. 2011). In der verwendeten Literatur tauchen weder angelsächsische noch deutsche Debatten der Wirtschaftsethik auf. 
All dies hinterlässt den Beigeschmack, dass hier keine philosophische Kritik der Rechtfertigung freier Märkte vorgenommen, sondern ein inkrementeller Verbesserungsvorschlag des ökonomischen Mainstreams versucht wurde, um freie Märkte (nun eben ohne irreführende Werbung) zukünftig noch besser rechtfertigen zu können.

Das Buch liefert eine Kritik der Bedingungen freier Märkte aus der Wohlfahrtsökonomie heraus, die jedoch an fast allen Axiomen festhält und nur eine einzelne, ganz bestimmte Annahme zur Debatte stellt und diese Kritik in die Wohlfahrtsökonomie integriert hat. Fragen mit wirtschaftsethischem Diskussionspotenzial wurden weitestgehend en passant zur Seite gewischt. Dies ist kein Problem, wenn man mit dieser Erwartung an das Buch herangeht. Titel und Klappentext sind dann aber ein wenig irreführend.

\section{Literaturverzeichnis}

Harrison, R./Newholm, T./Shaw, D. (2005): The Ethical Consumer, London u.a.: SAGE Publications Ltd.

Heidbrink, L./Schmidt, I./Ahaus, B. (2011): Die Verantwortung der Konsumenten. Über das Verhältnis von Markt, Moral und Konsum, Frankfurt a.M., New York: Campus Verlag.

Knobloch, U. (1994): Theorie und Ethik des Konsums, Bern, Stuttgart, Wien: Haupt Verlag.

Michel, K.-G. (1997): Konsumethik in der Wohlstandsgesellschaft, Paderborn, Zürich: Schöningh.

Thielemann, U. (1996): Das Prinzip Markt: Kritik der Ökonomischen Tauschlogik, Bern, Stuttgart, Wien: Haupt Verlag.

Thielemann, U. (2010): Wettbewerb als Gerechtigkeitskonzept. Kritik des Neoliberalismus, Marburg: Metropolis.

Ulrich, P. (1993): Transformation der ökonomischen Vernunft. Fortschrittsperspektiven der modernen Industriegesellschaft, 3., revidierte Auflage, Bern, Stuttgart, Wien: Haupt Verlag.

Ulrich, P. (2008): Integrative Wirtschaftsethik. Grundlagen einer lebensdienlichen Ökonomie, Bern, Stuttgart, Wien: Haupt Verlag. 